\title{
Interannual variability in the copepod populations of Georges Bank and the western Gulf of Maine
}

\author{
Carol Meise-Munns ${ }^{1}$, John Green ${ }^{1}$, Merton Ingham ${ }^{1}$, David Mountain ${ }^{2, ~ *}$ \\ ${ }^{1}$ National Marine Fisheries Service, Northeast Fisheries Center, South Ferry Road, Narragansett, Rhode Island 02882, USA \\ ${ }^{2}$ National Marine Fisheries Service, Northeast Fisheries Center, Woods Hole, Massachusetts 02543, USA
}

\begin{abstract}
Seasonal patterns of abundance of Calanus finmarchicus and Centropages typicus and that of all other copepods combined were characterized for outer Georges Bank ( $\geq 60 \mathrm{~m}$ depth) and the western Gulf of Maine for 1977 through 1984. An apparent drop in abundance and decay in seasonal patterns was observed in the early 1980 s. Significant correlations of annual mean residuals of individual copepod abundance between the 2 areas suggest that the copepod populations of Georges Bank are related to those of the western Gulf of Maine. Significant correlations between these annual mean residuals and environmental parameters, especially water column temperature, were found.
\end{abstract}

\section{INTRODUCTION}

What drives interannual variability in oceanic zooplankton populations? Analyses of long-term data sets which allow the examination of interannual variability of zooplankton populations are few. In the North Sea and Northeast Atlantic year-to-year changes have been interpreted to be due to climatic factors, such as changes in the North Atlantic current and localized wind events (Colebrook 1978, 1982a, b, 1985, 1986). Other experimental studies indicate that variability in plankton abundance and productivity may be influenced by environmental conditions, such as vertical structure of the water column (Mullin et al. 1985, Alcaraz et al. 1988), temperature (McLaren 1963, Davis 1987a) and water mass exchange (Kiørboe et al. 1988, Lindal \& Hernoth 1988). Davis (1987a) examined zooplankton production cycles on an annual scale, in the Northwestern (NW) Atlantic and other temperate oceans, and suggested that interannual variation in production may be attributable to temperature. After examining 5 yr of abundance data for the NW Atlantic Sherman et al. (1983) found coherence in the seasonal cycles of the plankton species examined but did not examine interannual variability.

During the period 1977 to 1987, the National Marine Fisheries Service (NMFS) Marine Monitoring and

\footnotetext{
- Authors appear in alphabetical order after the first
}

(c) Inter-Research/Printed in F. R. Germany
Prediction (MARMAP) program conducted broadscale sampling of zooplankton, ichthyoplankton and environmental parameters on the USA northeast continental shelf. In this paper 8 yr of MARMAP zooplankton abundance data (including the years covered by Sherman et al. 1983) from Georges Bank and the western Gulf of Maine are examined, in order to characterize the seasonal cycles of abundance for Calanus finmarchicus, the dominant spring copepod, Centropages typicus, the dominant copepod in the fall, and all other copepods (total copepods without C. finmarchicus and C. typicus). These data are further examined to identify significant departures from the characterized cycles and to relate these departures to interannual variability in environmental parameters during this period (e.g. Mountain \& Jessen 1987 , Ingham \& Wood 1988 and Wood \& Tang 1988).

\section{METHODS}

Field collection. Zooplankton samples were collected during 66 surveys conducted by vessels from the USA, Poland, the Soviet Union, and the German DemoCratic Republic during 1977 to 1984 , as part of the MARMAP sampling program of the northeastern shelf (Sherman 1980). Surveys occurred 6 to 12 times per year and sampled an array of stations ca 25 to $35 \mathrm{~km}$ apart on Georges Bank and in the Gulf of Maine (Fig. 1).

$0171-8630 / 90 / 0065 / 0225 / \$ 03.00$ 


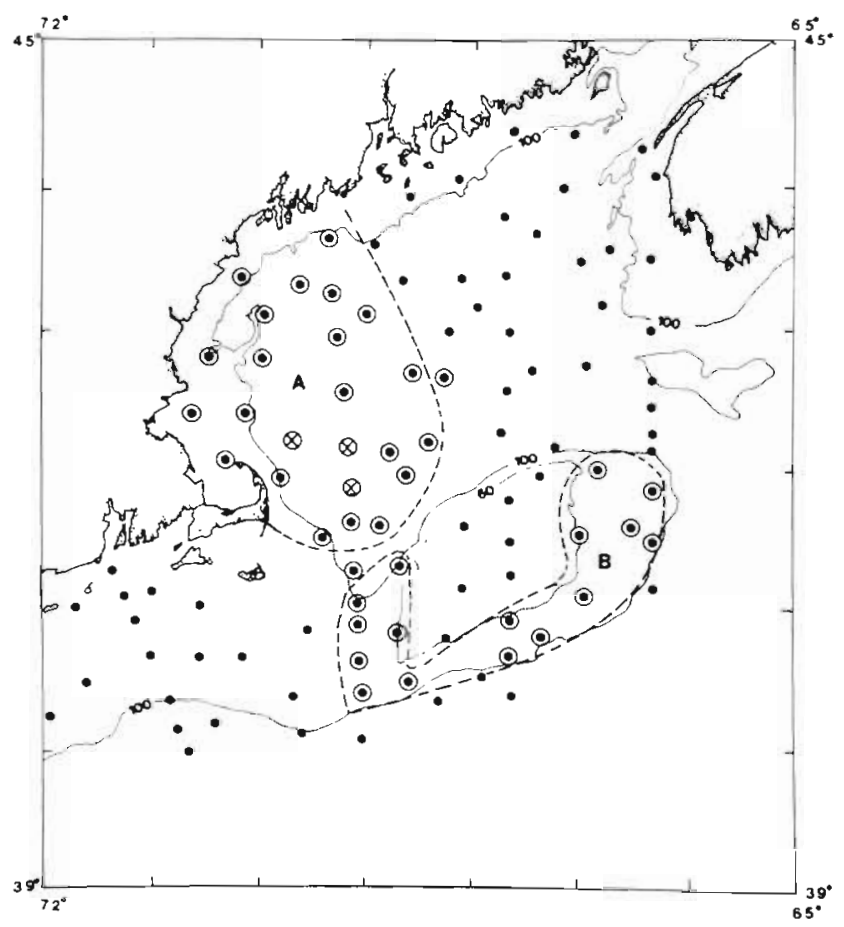

Fig. 1. MARMAP station locations in the Gulf of Maine and on Georges Bank, 1977 to 1984. Encircled stations were used for plankton data. All stations on Georges Bank (B) and those marked $\otimes$ in the western Gulf of Maine (A) were used for physical oceanography. Dashed line shows area boundaries

Georges Bank (GB) has 2 hydrographic regions: a shallow central portion $(<60 \mathrm{~m})$ which remains well mixed throughout the year, and a deeper region $(\geq 60 \mathrm{~m}$ ) which undergoes seasonal stratification. Only the deeper stratified region was chosen for analysis here because it develops upper water-column stability and temperature cycles similar to the Gulf of Maine. The western Gulf of Maine (WGOM) is characterized by distinct deep (to $240 \mathrm{~m}$ ) and irregular bathymetry and circulation (Emery \& Uchupi 1972, Butman et al. 1982). Because the upper water column in the WGOM has temperature and stratification characteristics similar to $\mathrm{GB}$ and because the majority of the Calanus finmarchicus population in the Gulf of Maine resides there, we analysed only those stations located in this portion of the Gulf (Fig. 1).

Oblique tows of $60 \mathrm{~cm}$ diameter bongo nets using $0.333 \mathrm{~mm}$ mesh for zooplankton were made through the water column from $5 \mathrm{~m}$ above the bottom or a maximum depth of $200 \mathrm{~m}$ to the surface. This mesh size catches, quantitatively, late stage copepodites and adults of the copepods examined here. It is this portion of the population that was analysed for this paper. The nets were towed at ship speeds ranging from 1.5 to 3.5 knots ( 2.8 to $6.5 \mathrm{~km} \mathrm{~h}^{-1}$ ), lowered at a wire speed of $50 \mathrm{~m} \mathrm{~min}^{-1}$ and retrieved at $20 \mathrm{~m} \mathrm{~min}^{-1}$ The volume of water filtered was measured with a flowmeter, and a time-depth recorder was used to record the towing profile of the sampler. Zooplankton samples from the $0.333 \mathrm{~mm}$ nets were sorted, identified and counted at the Plankton Sorting Center, Szczecin, Poland.

Measurements of temperature and salinity through the water column were made at each station on 31 of the cruises. The measurements were made using water sampling bottles with reversing thermometers at up to 15 standard depths. The accuracy of the observations is $\mathrm{Ca} \pm 0.02^{\circ} \mathrm{C}$ for temperature and $\pm 0.01 \mathrm{ppt}$ for salinity. Chlorophyll a (chl a) samples were collected from the same water sampling bottles and analyzed using the methods described by Evans \& O'Reilly (1980). The broad-based sampling protocol described above was designed to examine large-scale (in time and space) changes in the physical and biological environment. Therefore the analysis described here was confined to interpretations of interannual differences over a large $(400 \mathrm{~km})$ spatial scale.

Analysis. Zooplankton data were grouped into $10 \mathrm{~d}$ intervals for both areas of study. The data were natural $\log (+1)$ transformed to stabilize the variance and means calculated for the $10 \mathrm{~d}$ intervals. These intervals are short in terms of the population dynamics of the copepods and give a better representation of the seasonal cycle than cruise means. Harmonic regressions over an annual cycle were fit to the time series using least squares analysis (Table 1, Fig. 2). Because of the interdependent nature of most planktonic population processes, estimates of abundance through time are autocorrelated. An autoregressive term (a lagged abundance variable) was used to remove autocorrelation in the residuals of the harmonic model, allowing for a more accurate determination of the model parameters (Box \& Jenkins 1976). After the harmonic and lag term are applied to the data, any departures from the model are more likely to be caused by some external signal. Models were fit to the abundance (numbers per hundred cubic meters) of Calanus finmarchicus and Centropages typicus and to all other copepods for $G B(\geq 60 M)$ and WGOM. Interannual variation was apparent in the residuals of the models. The residuals were summarized by showing the annual mean residual for each of the years analyzed. The residuals were presented in this manner (Fig. 3) to exemplify either the magnitude or the consistency in sign of the difference between years.

Environmental data showed interannual variation, particularly in the early 1980's (Mountain \& Jessen 1987. Ingham \& Wood 1988, Wood \& Tang 1988) (Fig. 4). To investigate any possible environment-tozooplankton linkages, 3 variables which relate to physiological or feeding conditions were chosen: wind stress, water temperature and water column stratifica- 
Table 1 Harmonic regression models and F-statistics for 1977 to 1984 copepod abundance. The following terms apply: SA = $\sin (0.0172$ Julian Day); $C A=\cos (0.0172$ Julian day); LCop, LCal, LCen = lagged autoregressive term; MSE = mean square error; $\mathrm{n}=$ number of observations; $\mathrm{F}=\mathrm{F}$-statistic for the regression

\begin{tabular}{|c|c|c|c|}
\hline & MSE & $\mathrm{n}$ & F \\
\hline \multicolumn{4}{|l|}{ Georges Bank } \\
\hline Calanus finmarchicus $=6.83+0.76 \mathrm{SA}-1.28 \mathrm{CA}+0.18 \mathrm{LCa}]$ & 1.7 & 107 & 34.83 \\
\hline Centropages typicus $=4.82-1.93 \mathrm{SA}+0.34 \mathrm{LCen}$ & 3.76 & 102 & 59.81 \\
\hline Total copepods $=7.07-0.55 \mathrm{CA}+0.32 \mathrm{LCop}$ & 0.87 & 107 & 15.05 \\
\hline \multicolumn{4}{|l|}{ Western Gulf of Maine } \\
\hline Calanus finmarchicus $=5.50+0.61 \mathrm{SA}-0.72 \mathrm{CA}+0.34 \mathrm{LCal}$ & 2.14 & 129 & 25.57 \\
\hline Centropages typicus $=3.80-1.82 \mathrm{SA}+0.45 \mathrm{LCen}$ & 3.28 & 129 & 104.33 \\
\hline Total copepods $=8.06-0.29 \mathrm{SA}-0.63 \mathrm{CA}+0.23 \mathrm{LCop}$ & 0.57 & 129 & 25.41 \\
\hline
\end{tabular}

tion. Wind stress is a measure of the wind force acting on the sea surface. It produces turbulence and mixing and in this case was used as a proxy for these parameters. The effect of turbulence on plankton is under debate in the current literature (Buckley \& Lough 1987 ,
Alcaraz et al. 1988, Rothchild \& Osborn 1988, Sunby \& Fossum 1989). The correlations in this study were run to examine the gross effects of turbulence on the copepod populations (i.e. increase or decrease) examined here. Temperature is known to affect the
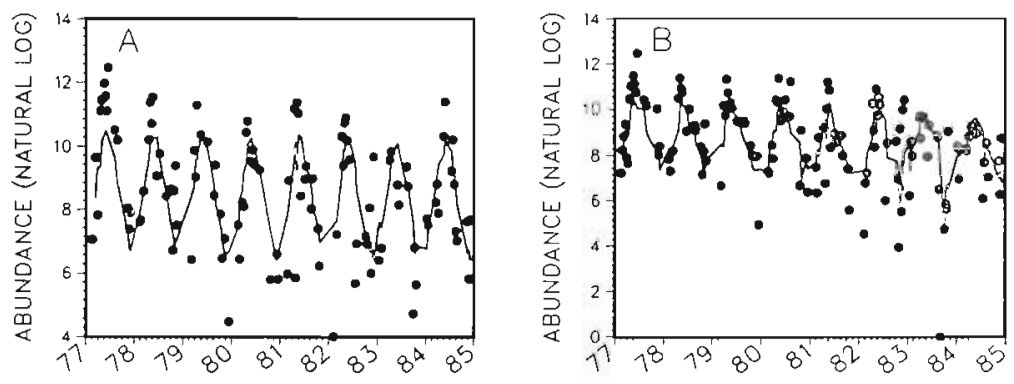

Fig. 2. Ten-day means of natural log $(+1)$ transformed copepod abundance data (points) with the fitted model line (line). Model line was generated with the regressions in Table 2. (A) Calanus finmarchicus on Georges Bank; (B) C. finmarchicus in western Gulf of Maine; (C) Centropages typicus on Georges Bank; (D) C. typicus in western Gulf of Maine; (E) all other copepods on Georges Bank; (F) all other copepods in western Gulf of Maine
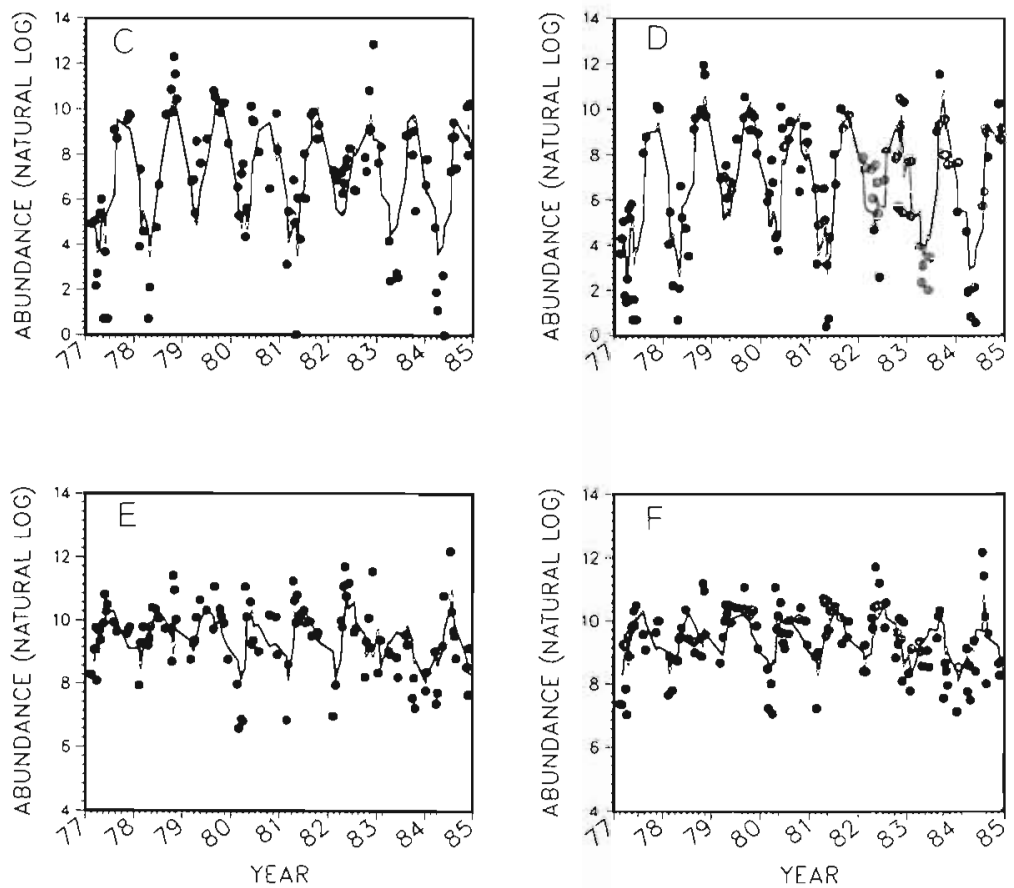

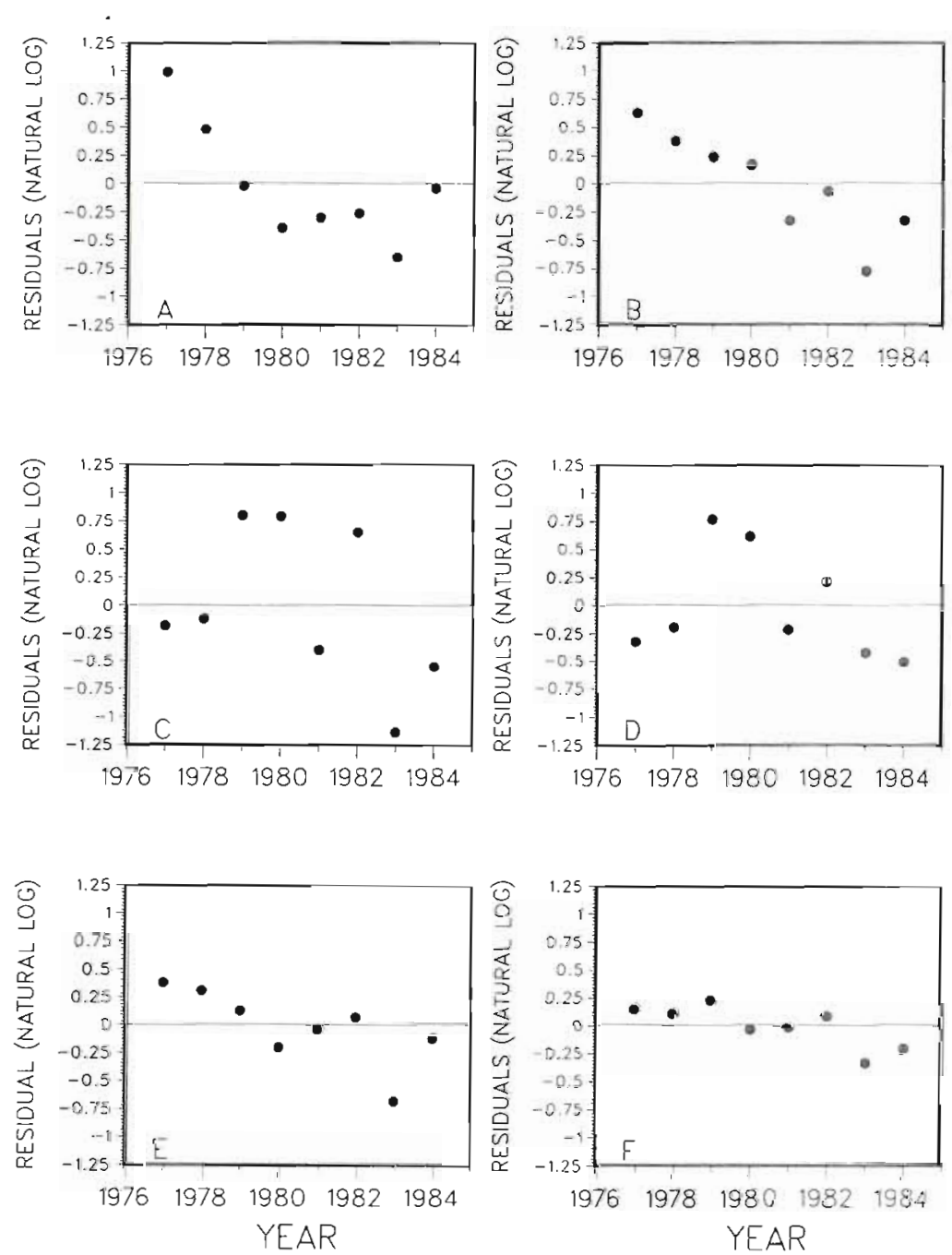

Fig. 3. Annual mean residuals from the harmonic models of copepod abundances for both Georges Bank and western Gulf of Maine, 1977 to 1984. (A) Calanus finmarchicus on Georges Bank; (B) C. finmarchicus in western Gulf of Maine; (C) Centropages typicus on Georges Bank; (D) C. typicus in western Gulf of Maine; (E) all other copepods on Georges Bank; (F) all other copepods in western Gulf of Maine

physiological rates of all animals. Work by Vidal $(1980 \mathrm{a}, \mathrm{b})$ has shown how growth and production of copepods can be affected to varying degrees with changes in this parameter. Water column stratification has been shown to be important both as a concentrating mechanism (Buckley \& Lough 1987) and as a boundry to frontal zones (Kiørboe \& Johansen 1986, Richardson et al. 1986). The spring and fall bloom in concentration of chl a was also examined by calculating a depth-averaged seasonal mean for each period. This was used as a measure of standing stock of potential food. Correlation analysis was used to look for population level effects of these parameters.

The time periods chosen for the environmental data were determined by 2 constraints. These were choosing periods for individual environmental parameters which were biologically meaningful and for which there were sufficient data. For physical data, generally, there was one cruise in winter, one in spring and one in the fall, with an occasional late summer cruise. The time periods shown for each environmental variable indicate the most biologically conservative starting and ending point throughout the 8 yr period that allowed incorporation of these cruises (Table 2). For Centropages typicus, which is a dominant in the fall, any environmental observations from the late summer and late fall periods were averaged to represent conditions during the fall period. Chl a observations were taken on 31 of the cruises. Those observations taken during the spring and fall bloom of both phytoplankton and zooplankton were used in this analysis. Wind data were also averaged during periods of the spring and fall bloom to determine the effects of mixing on the copepod species involved.

Mountain \& Jessen (1987) showed that the spatial variability of water properties across the Gulf of Maine is quite large. To separate temporal from spatial variation, they chose 3 regularly occupied MARMAP stations in Wilkenson Basin to be an index of properties of the WGOM. The same stations were used in this analy- 

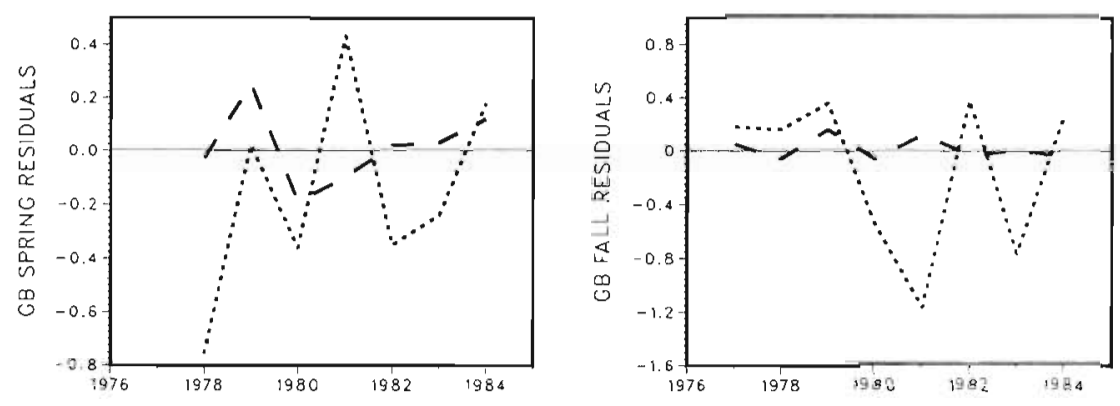

Fig. 4. Mean environmental residuals for Georges Bank and the western Gulf of Maine. Dotted lines represent integrated $(0$ to $50 \mathrm{~m}$ ) water-column temperature $\left({ }^{\circ} \mathrm{C}\right)$, dashed lines watercolumn stratification (density difference 0 to $50 \mathrm{~m}$ ). The following time periods apply: spring temperature (Julian Day 130 to 165), fall temperature (180 to 365 ), spring stratification (130 to 165$)$, fall stratification (180 to 365), for both GB and WGOM
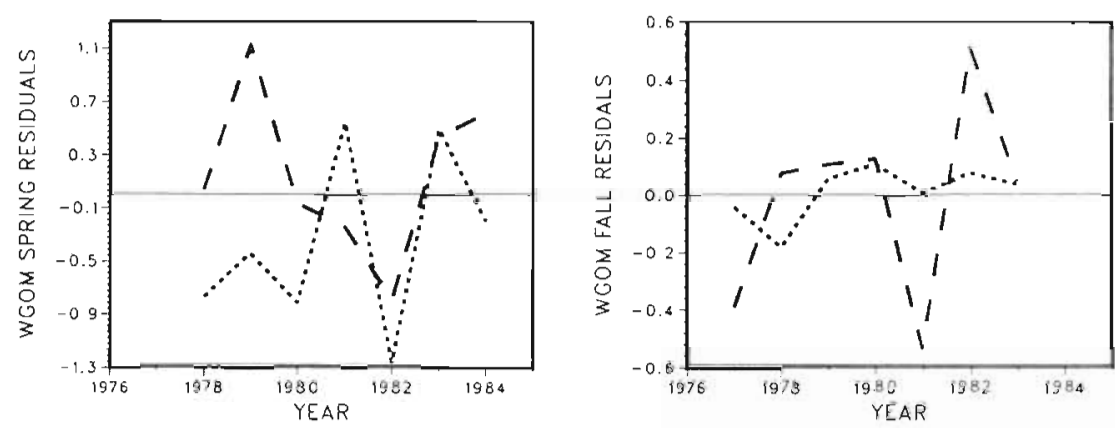

sis (Fig. 1). On Georges Bank 16 stations between the 60 and $100 \mathrm{~m}$ isobaths were chosen to represent conditions in the stratified part of the bank (Fig. 1). Following the methods of Mountain \& Jessen (1987), each station in each region was weighted in proportion to the fraction of the area represented. On each cruise, when at least half the selected stations were occupied, areal weighted average water properties were calculated. The average temperature between 0 and $50 \mathrm{~m}$ was used to represent the upper layer for both regions. The density difference between 0 and $50 \mathrm{~m}$ was used as an index of stratification of the water column (Hopkins \& Garfield 1979).

The annual cycles of temperature and stratification were calculated using the regression method described by Mountain \& Holzwarth (unpubl.). To determine interannual variability in the water properties, the annual cycle was subtracted from the data, yielding residuals which are portrayed in Fig. 4.

Wind stress data were provided by the Pacific Fisheries Environmental Group (NOAA, NMFS). This information is generated by a US Navy computer program driven by surface atmospheric pressure observations for the northern hemisphere; see Bakun (1973) for method. Values of wind stress are routinely computed on a $3^{\circ} \times 3^{\circ}$ (latitude $\times$ longitude) grid, and 2 of these grid points, $42^{\circ} \mathrm{N} 66^{\circ} \mathrm{W}$ and $42^{\circ} \mathrm{N} 69^{\circ} \mathrm{W}$, were selected for this study and daily averages calculated. These values were grouped into time intervals (see Table 1) and means taken for correlation with copepod mean residuals (described below)
Spearman correlations were generated between copepod annual mean residuals from the harmonic regressions from both areas and between copepod mean residuals and the environmental residuals and chlorophyll means.

\section{RESULTS}

Significant annual cycles were found for all species of copepods in both areas (Table 1, Fig. 2). Summary deviations (residuals) for each year are plotted in Fig. 3. For Calanus finmarchicus in both areas and Centropages typicus on Georges Bank, the years 1981 to 1984 show large and/or continuous-in-sign deviations from the previous 4 yr. Total copepods in both areas and $C$. typicus in the WGOM show a large difference in the residuals from 1982 to 1983 . Summary deviations for temperature and stratification are plotted in Fig. 4.

Significant correlation coefficients for all environmental variables with copepod mean residuals and between copepod residuals in both areas are reported in Table 2. Nonparametric statistics increase the probability of making a Type 2 error, therefore we report correlations with probabilities up to 0.15 .

\section{DISCUSSION}

The strongest correlations reported above are between the annual residuals of copepod abundance in the WGOM and on Georges Bank. The waters on 
Table 2. Spearman correlation coefficents between the copepod annual mean residual from the harmonic regression on Georges Bank (GB) and western Gulf of Maine (WGOM) and between the copepod annual mean residual of each area and environmental mean residual. Only significant correlations are shown. NS: not significant; $r$ : correlation coefficent; p: probability level; $n$ : sample size; Julian Day is the time period that the environmental residual was calculated for

\begin{tabular}{|c|c|c|c|c|}
\hline & & Calanus finmarchicus & Centropages typicus & Total copepods \\
\hline $\begin{array}{l}\text { GB abundance vs WGOM abundance } \\
\mathrm{n}=8\end{array}$ & $\begin{array}{l}r \\
(p)\end{array}$ & $\begin{array}{c}0.83 \\
(0.01)\end{array}$ & $\begin{array}{c}0.95 \\
(0.00)\end{array}$ & $\begin{array}{c}0.90 \\
(0.00)\end{array}$ \\
\hline \multicolumn{5}{|l|}{ Western Gulf of Maine } \\
\hline $\begin{array}{l}\text { Temperature } \\
\mathrm{n}=7 \\
\text { Julian Day }\end{array}$ & $\begin{array}{l}\mathrm{r} \\
(\mathrm{p})\end{array}$ & $\begin{array}{c}-0.65 \\
(0.11) \\
130-165\end{array}$ & $\begin{array}{c}0.71 \\
(0.07) \\
180-365\end{array}$ & NS \\
\hline $\begin{array}{l}\text { Chl a } \\
\quad n=6 \\
\text { Julian Day }\end{array}$ & $\begin{array}{l}r \\
(p)\end{array}$ & $\begin{array}{l}-0.82 \\
(0.04) \\
61-150\end{array}$ & NS & NS \\
\hline $\begin{array}{l}\text { Wind stress } \\
\mathrm{n}=8 \\
\text { Julian Day }\end{array}$ & $\stackrel{\Gamma}{(p)}$ & NS & NS & $\begin{array}{c}0.57 \\
(0.13) \\
31-120\end{array}$ \\
\hline \multicolumn{5}{|l|}{ Georges Bank } \\
\hline Temperature & & NS & NS & NS \\
\hline Chl a & & NS & NS & NS \\
\hline $\begin{array}{l}\text { Wind stress } \\
n=8 \\
\text { Julian Day }\end{array}$ & $\begin{array}{c}r \\
(p)\end{array}$ & $\begin{array}{l}\text { NS } \\
\text { NS }\end{array}$ & $\begin{array}{l}\text { NS } \\
\text { NS }\end{array}$ & $\begin{array}{c}0.59 \\
(0.11) \\
31-120\end{array}$ \\
\hline
\end{tabular}

Georges Bank originate primarily from the near-surface waters in the western Guif of Maine (Hopkins \& Garfield 1981). Once on the bank the water has a mean residence time of about 2 mo (Csanady \& Magnell 1988), comparable with the generation time of the copepods considered here. It is likely that the copepod populations on GB are, to a significant extent, made up of individuals which originated from the WGOM (Bigelow 1927, Davis 1984). With the physical oceanographic connection between the regions, the correlations between annual residuals in the WGOM and on $G B$ are not surprising and suggest that the copepod variability on Georges Bank originates, to a large part, in the WGOM. Much of the springtime population of Calanus finmarchicus is thought to originate from the overwintering population in the WGOM (Davis 1987b). Colebrook (1982a) has shown that for copepod populations in the North Sea it is the overwintering population that determines maximum population size for each new year. The significant correlations shown here suggest that this may also be the case for $G B$ copepod populations.

The negative relationship shown in Table 2 for WGOM Calanus finmarchicus and spring temperature $\left(5\right.$ to $8^{\circ} \mathrm{C}$ ) is not unexpected. C. finmarchicus is known to be a cold-water species (range is from $-2^{\circ}$ to $20^{\circ} \mathrm{C}$ ) (Marshall \& Orr 1955). Although their tolerable temperature range is broad, Davis (1987a) suggests that these copepods are not productive at temperatures above $12^{\circ} \mathrm{C}$. Their oxygen rate doubles from 0 to $10^{\circ} \mathrm{C}$ and above $10^{\circ} \mathrm{C}$ rises at an even faster rate (Marshall \& Orr 1955). Experimental evidence from Vidal $(1980 a, b)$ makes it clear that in the laboratory, $C$. pacificus has better growth and production at colder temperatures. Our findings lend support to this observation, at the population level, in the field for $C$. finmarchicus.

The negative relationship seen in this study between WGOM Calanus finmarchicus and March-May chlorophyll is probably attributable to grazing pressure. Work by Cox et al. (1983) and Mackus \& Boyd (1979) suggest that high concentrations of Calanus sp. and chl a do not co-occur in the field because Calanus sp. will quickly graze down high concentrations of phytoplankton, simply causing a mismatch between areas of high abundance of these 2 variables. A negative relationship may also occur when food is limiting. If this were the case in the WGOM, one would expect to see other significant correlations, such as a positive correlation at some earlier time interval between $C$. finmarchicus and chl a or, as discussed below, between wind stress and $C$. finmarchicus.

Centropages typicus is a warm-water species, smaller than Calanus finmarchicus, that does not migrate vertically (Bigelow 1926, Clarke 1933). Bigelow (1926) suggested minimum breeding tem- 
peratures for $C$. typicus to be 8 to $12^{\circ} \mathrm{C}$. WGOM fall upper-layer temperatures range from 8 to $12^{\circ} \mathrm{C}$ (Manning \& Holzwarth 1990, their Fig. 250) and thus lie at the lower end of the acceptable breeding range. Because of this, one would expect WGOM C. typicus abundance to show a positive relationship with fall temperature.

The positive relationship between the annual mean abundance of all other copepods and February-April wind stress and the lack of relationships between abundance and chlorophyll, temperature and stratification are somewhat puzzling. This contrasts with work by Alcaraz et al. (1988) which showed a negative relationship between turbulence and copepod abundance due to changes in demographic composition and increased metabolic activity. February to April is early in the seasonal cycle of these copepods, and turbulence may have less of an impact during this period. A positive relationship might be expected if phytoplankton as food were limiting. Higher turbulence during this time of year might increase chlorophyll or primary production through nutrient mixing, and the copepods would benefit in this fashion. It might also increase contact rates between copepods and their phytoplankton prey or, on the negative side, their predators (Rothschild \& Osborn 1988). If an increase in contact rates between copepods and phytoplankton were the cause of this positive correlation, one would expect to see the same relationship for Calanus finmarchicus and Centropages typicus also. It also seems logical to expect significant correlations between phytoplankton and total copepods. The positive relationship reported here might become more explicit when examined on an individual species basis.

Colebrook (1978, 1982a, b, 1985, 1986) suggested temperature, stratification and other physical environmental variables can be important in the dynamics of zooplankton seasonal cycles and geographic distribution in the North Sea. He proposed that interannual variability in the plankton community of the North Sea is determined primarily by specific rates and fluxes of physical processes and of the plankton's own biological processes. In his 1986 paper, Colebrook suggested that temperature influences the rate and timing of the spring bloom. Vidal's (1980a, b) laboratory studies showed physiological mechanisms by which temperature may have influence over the zooplankton community. Our study provides field evidence for the linkage between the WGOM and GB oceanic systems and between oceanic environmental events and the plankton community in these 2 areas. Although the time series of data available to us are not as long as Colebrook's, there is evidence of similar, although more localized, relationships. The work of Vidal (1980a, b) and others gives potential biological meaning to some of these relationships. Even with a 7 yr time series of data, interannual variability is difficult to elucidate and only pronounced relationships can be identified, such as the interrelationship between the WGOM and Georges Bank copepod populations and the importance of temperature.

On the scale examined in this study, stratification and wind do not appear to have any discernible effect on these populations. The specific mechanisms that determine the observed relationships between environmental factors and copepod populations and more subtle relationships that may be in these data are not addressed, because of the shortness of the time series and the broad-based nature of the sampling. To clarify these, the exact nature of the relationships must be evaluated and defined in detailed in situ and laboratory studies and with a longer time series.

Acknowledgements. The authors thank their colleagues at the National Marine Fisheries Service in Narragansett, RI, Woods Hole, MA and Sandy Hook, NJ, USA. Special thanks are given to Wayne R. Munns (of SAIC), Michael Fogarty and Michael Pennington for useful discussion and advice during this project. Jay O'Reilly and Chris Zetlin provided us with chlorophyll data. Frank Almeida provided graphics help. We also thank Ed Cohen and Sharon MacLean for critical comments on the manuscript.

\section{LITERATURE CITED}

Alcaraz, M., Saiz, E., Marrassé, C., Vagué, D. (1988). Effects of turbulence on the development of phytoplankton biomass and copepod populations in marine microcosms. Mar. Ecol. Prog. Ser. 49: 117-125

Bakun, A. (1973). Coastal upwelling indices, west coast of North America, 1946-71. U.S. Dept. of Commerce, Wash., D.C. NOAA Tech. Rep. NMFS-SSRF-671, p. 1-103

Bigelow, H. B. (1926). Plankton of the offshore waters of the Gulf of Maine. Bull. Bur. Fish., Wash. 40: 1-509

Bigelow, H. B. (1927). Physical oceanography of the offshore waters of the Gulf of Maine. Bull. Bur Fish., Wash. 40: 511-1027

Box, G. P., Jenkins, G. M. (1976). Time series analysis forecasting and control. In: Robinson, E. (ed.) Holden Day, Oakland

Buckley, L. J., Lough, R. G. (1987). Recent growth, biochemical composition and prey field of larval haddock (Melanogrammus aegletinus) and Atlantic cod (Gadus movrhoe) on Georges Bank. Can. J. Aquat. Sci. 44: 14-25

Butman, B., Beardsley, R. C., Magnell, B., Frye, D., Vermersch, J. A., Schlitz, R., Limeburner, L., Wright, W. R., Noble, M. A. (1982). Recent observations of the mean circulation on Georges Bank. J. phys. Oceanogr. 12: 569-591

Clarke, G. L. (1933). Diurnal migration of plankton in the Gulf of Maine and its correlation with submarine irradiation. Biol. Bull. mar. biol. Lab., Woods Hole 65: 402-436

Colebrook, J. M. (1978). Continuous plankton records: zooplankton and environment, north-east Atlantic and North Sea, 1948-1975. Oceanol. Acta 1: 9-23

Colebrook, J. M. (1982a). Continuous plankton records: phy- 
toplankton, zooplankton and the environment, north-east Atlantic and the North Sea, 1958-1980. Oceanol. Acta 5: $473-480$

Colebrook, J M. (1982b). Continuous plankton records: seasonal variations in the distribution and abundance of plankton in the North Atlantic Ocean and the North Sea. J. Plankton Res. 4: 435-462

Colebrook, J. M. (1985). Sea surface temperature and zooplankton, North Sea, 1948 to 1983. J Cons. int. Explor. Mer 42: 179-185

Colebrook, J. M. (1986). Environmental influences on long-term variability in marine plankton. Hydrobiologia 142: 309-325

Cox, J. L., Willason, S., Harding, L. (1983). Consequences of distributional heterogeneity of Calanus pacificus grazing. Bull. mar. Sci. 33: 213-226

Csanady, G. T., Magnell, B. A. (1988). Mixing processes. In: Bakus, R. A., Bourne, D. W. (eds.) Georges Bank. MIT Press, Cambridge, p. 163-169

Davis, C. S. (1984). Interaction of a copepod population with the circulation on Georges Bank. J. mar. Res. 42: 573-590

Davis, C. S. (1987a). Components of the zooplankton production cycle in the temperate ocean. J. mar. Res. 45: 947-983

Davis, C. S. (1987b). Zooplankton Life Cycles. In: Bakus, R. A., Bourne, D. W. (eds.) Georges Bank. MIT Press, Cambridge, p. 256-267

Emery, K. O., Uchupi, E. (1972). Western North Atlantic Ocean: topography, rocks, structure, water life, and sediments. Am. Ass. Pet. Geol. Mem. 17: 1-532

Evans, C., O'Reilly, J. (1980). A manual for measurement of chlorophyll $\mathrm{A}$, net phytoplankton and nanoplankton. Biomass Handbook no. 9. SCAR/SCOR/IABO/ACMRR

Hopkins, T S., Garfield, N III. (1979). Gulf of Maine intermediate water. J. mar. Res. 37: 103-139

Hopkins, T. S., Garfield, N. III. (1981). Physical origins of Georges Bank water. J. mar. Res. 39: 465-500

Ingham, M. C., Wood, G. E. (1988). Air temperature and wind speed anomalies in 1981-1987 at coastal weather stations in the northeastern USA. NAFO SCR Doc. 88/85. Serial No. N1537 Northwest Atlantic Fisheries Org., Dartmouth, Nova Scotia, Canada

Kiørboe, T., Munk, P., Richardson, K., Christensen, V., Paulsen, H. K. (1988). Plankton dynamics and larval herring growth, drift and survival in a frontal area. Mar. Ecol. Prog. Ser. 44: 205-219

Kiørboe, T., Johansen, K. (1986). Studies of larval herring (Clupea harengus L.) patch in Buchan area. IV Zooplankton distribution and productivity in relation to hydrographic features. Dana 6: 37-51

Lindahl, O., Hernroth, L. (1988). Large-scale and long-term variations in the zooplankton community of the Gullmar fjord, Sweden, in relation to advective processes. Mar. Ecol. Prog. Ser. 43: 161-171

This article was submitted to the editor
Mackus, D. C., Boyd, C. M. (1979). Spectral analysis of zooplankton spatial heterogeneity. Science 204: 62-64

Manning, J., Holzwarth, T (1990). Description of oceanographic conditions on the North-East Continental Shelf of the USA, 1977-1985. NEFC Ref. Doc. 90-04

Marshall, S. M. Orr, A. P. (1955). The Biology of a Marine Copepod. Oliver and Boyd, London

McLaren, I. A. (1963). Effects of temperature on growth of zooplankton and the adaptive value of vertical migration. J. Fish. Res. Bd Can. 20: 685-727

Mountain, D. G., Jessen, P. F. (1987). Bottom waters of the Gulf of Maine, 1978-1983. J. mar. Res. 45: 319-345

Mountain, D. G., Holzwarth, T. J. (1989). Surface and bottom temperature distributions for the northeast continental shelf. NOAA Tech. Mem. NMFS-F/NEC (in preparation)

Mullin, M. M., Brooks, E. R., Reid, F. M., Napp. J., Stewart. E. F. (1985). Vertical structure of nearshore plankton off Southern California: a storm and a larval fish food web. Fish. Bull. U.S. 83: 151-170

Richardson, K., Heath, M. R., Pedersen, S. M. (1986). Studies of larval herring (Clupea harengus L.) patch in Buchan area. III. Phytoplankton distribution and primary productivity in relation to hydrographic features. Dana 6: 25-36

Rothschild, B. J., Osborn, T R. (1988). Small-scale turbulence and plankton contact rates. J. Plankton Res. 10: 465-474

Sherman, K. (1980). MARMAP, a fisheries ecosystem study of the Northwest Atlantic Fluctuations in ichthyoplankton-zooplankton components and their potential for impact on the system. In: Diemer, F. P., Vernberg, F. J., Mirkes, D. Z. (eds.) Advanced concepts in ocean measurements for marine biology. Belle W Baruch Inst. Mar Biol. Coastal Res., Univ. South Carolina Press, Columbia, p. 3-37

Sherman, K., Green, J., Goulet, J., Ejsymont, L. (1983). Coherence in zooplankton of a large marine ecosystem. Fish Bull. U.S. 81: 855-862

Sunby, S., Fossum, P. (1989). Feeding conditions of North East Arctic (Arcto-Norwegian) cod larvae compared to the Rothschild-Osborn theory on small-scale turbulence and plankton contact rates. Int. Counc. Explor. Sea G: 19

Vidal, J. (1980a). Physioecology of Zooplankton. I. Effects of phytoplankton concentration, temperature, and body size on the growth rate of Calanus pacificus and Pseudocalanus sp. Mar Biol. 56: 111-134

Vidal, J. (1980b). Physioecology of Zooplankton. IV Effects of phytoplankton concentration, temperature, and body size on the production rate of Calanus pacificus. Mar. Biol. 56 $147-202$

Wood, G. B., Tang, V. (1988). Sea-surface temperature anomalies off the northeastern USA during 1981-1986. NAFO SCR Doc. 88/84. Serial No. N1536. Northwest Atlantic Fisheries Org., Dartmouth, Nova Scotia, Canada

Manuscript first received: January 4, 1990

Revised version accepted: May 31, 1990 